\title{
Google Earth Engine Applications
}

\author{
Onisimo Mutanga ${ }^{1, *(-)}$ and Lalit Kumar ${ }^{2}(\mathbb{C}$ \\ 1 School of Agricultural, Earth and Environmental Sciences, University of KwaZulu Natal, P. Bag X01 \\ Scottsville, Pietermaritzburg 3209, South Africa \\ 2 Ecosystem Management, School of Environmental and Rural Science, University of New England, Armidale, \\ NSW 2351, Australia; lkumar@une.edu.au \\ * Correspondence: Mutangao@ukzn.ac.za
}

Received: 8 March 2019; Accepted: 11 March 2019; Published: 12 March 2019

Keywords: cloud computing; big data analytics; long term monitoring; data archival; early warning systems

\section{Introduction}

The Google Earth Engine (GEE) is a cloud computing platform designed to store and process huge data sets (at petabyte-scale) for analysis and ultimate decision making [1]. Following the free availability of Landsat series in 2008, Google archived all the data sets and linked them to the cloud computing engine for open source use. The current archive of data includes those from other satellites, as well as Geographic Information Systems (GIS) based vector data sets, social, demographic, weather, digital elevation models, and climate data layers.

The easily accessible and user-friendly front-end provides a convenient environment for interactive data and algorithm development. Users are also able to add and curate their own data and collections, while using Google's cloud resources to undertake all the processing. The end result is that this now allows scientists, independent researchers, hobbyists, and nations to mine this massive warehouse of data for change detection, map trends, and quantify resources on the Earth's surface like never before. One does not need the large processing powers of the latest computers or the latest software, meaning that resource-poor researchers in the poorest nations of the world have the same ability to undertake analysis as those in the most advanced nations.

The purpose of this special issue was to solicit papers that take advantage of the Google Engine cloud computing geospatial tools to process large data sets for global applications. Special priority was given to papers from developing nations on how the availability of GEE data and processing has enabled new research that was difficult or impossible before. Key areas covered processing shortcomings, programming, and difficulties in handling data in the cloud atmosphere. We are pleased to report that a total of 22 papers were published in this special issue, covering areas around vegetation monitoring, cropland mapping, ecosystem assessment, and gross primary productivity, among others. A plethora of data sets used ranged from coarse spatial resolution data such as MODIS (Moderate Resolution Imaging Spectroradiometer) to very high-resolution data sets (Worldview -2) and the studies covered the whole globe at varying spatial and temporal scales.

Since its inception in 2010, Google Earth engine usage was investigated using articles drawn from a total of 158 journals. The study showed a skewed usage towards developed countries as compared to developing regions such as Africa [1], with Landsat being the most widely used data set.

This editorial categorized the papers into five main themes, whose contributions are summarized.

\subsection{Vegetation Mapping and Monitoring}

A number of articles examined the utility of GEE in vegetation mapping and monitoring. This includes the global estimation of key biodiversity variables such as Leaf Area Index (LAI), Fraction 
of Absorbed Photosynthetically Active Radiation (FAPAR), Fraction Vegetation Cover (FVC), and Canopy water content (CWC) using MODIS historical data [2]. At a planetary scale in Vietnam [3], mapped vegetation using MODIS derived EVI products and the GEE web based application. Using a user defined baseline period, they could monitor the degradation or improvement of vegetation and the impact of mitigation efforts by the Vietnam government. A related study in a Chinese nature reserve used multi seasonal Landsat TM composites to map vegetation and general landcover by minimizing cloud cover and terrain effects. A combination of spectral vegetation indices, terrain ancillary data, and simple illumination transformation could predict vegetation classification with accuracy above $70 \%$ [4]. A more refined and accurate $30 \mathrm{~m}$ NDVI composite, spanning the past 30 years, was developed for the United States of America using the Google Engine cloud-based planetary processing platform [5]. Missing data due to clouds was filled by using a climate driven modelling approach and data was produced at multiple scales [5]. Using Google Engine, an ecosystem assessment study in a Brazilian semi-arid landscape showed that high spatial resolution data (Worldview) could yield higher classification accuracy compared to medium resolution Landsat TM, with full spectral resolution information [6]. Trees, shrubs, and bare land were classified, with a clear distinction between trees and shrubs, a mammoth task using prior data sets.

Attention was also paid towards rangeland monitoring using long term satellite data in a cloud computing environment. Specifically, a total of 17 pastureland maps were produced in Brazil using MODIS data from 2000 to 2016 with an accuracy above $80 \%$ [7]. Results showed an increase in pasture area for most areas analyzed. In another study, [8] integrated GEE and Sentinel 2 data in a machine learning environment to map sea grasses in the Aegean and Iron seas. They could successfully map the seasonal and inter-annual variation of seagrasses up to a depth of $40 \mathrm{~m}$.

\subsection{Landcover Mapping}

A number of studies assessed land cover dynamics at different spatial scales. Taking advantage of GEE, which provides data access and advanced analytical techniques on big data, [9] used the Bayesian Updating of Land Cover (BULC) algorithm to fuse Landsat data with GlobCover 2009, thereby improving the spatial resolution of the global output from $300 \mathrm{~m}$ to $30 \mathrm{~m}$ in Brazil. The approach is widely applicable, since it employs an unsupervised algorithm, which does not require intensive ground truthing data [9]. The potential of GEE was also demonstrated in handling huge long term data sets at a global scale to analyze the impact of land cover change on surface urban heat island, taking advantage of the already established climate tool Engine to extract huge land surface temperature data [10]. More than 6000 Landsat images from 2000 to 2011 were processed.

The problem of cloud cover is not new in remote sensing. The availability of time series data and GEE platform facilitated the development of algorithms that solve the cloud cover and terrain effects problems of land cover mapping in a Chinese protected area [4]. The cloud computing platform also facilitated computation of spectral vegetation indices [11] from multi-seasonal Landsat data as well as illumination normalization algorithms, yielding successful land cover classification results. Apart from Landsat data, another study employed high resolution Sentinel 1 and 2 satellite data to map wetland extent at a provincial scale in Newfoundland, Canada [12]. The study produced the first detailed regional wetland map, leveraging on high resolution Sentinel SAR and optical data, the GEE computational power, and advanced machine learning algorithms.

\subsection{Agricultural Applications}

Remotely sensed agricultural applications that include crop yield estimation, crop area mapping, pests and diseases vulnerability, and suitability assessments, among others, are critical for sustaining productivity and food security. This issue reports on a number of studies that used GEE cloud computing for agricultural applications across varying scales. The GEE platform provided an opportunity to fuse Terra MODIS data and Landsat to estimate Gross Primary Productivity of seven crops in Montana, USA from 2008-2015 at $30 \mathrm{~m}$ spatial resolution [11]. The estimated cropland 
productivity patterns and their seasonal variations compared favorably with the country level crop data. High spatial resolution Worldview 2 data was also used to map small holder heterogeneous cropland areas in the African environment of Mali, using ensemble rules [13]. The cloud platform, with high processing capabilities, allowed the computation of a number of ensemble rules to optimize classification accuracy. At a continental scale, cropland and non-cropland areas were mapped for the entire continent of Africa using a combination of 10-day Sentinel data and 16-day Landsat TM data. 30 $\mathrm{m}$ resolution composites were generated using the satellite data, together with elevation data yielding a 30-m slope layer derived from the Shuttle Radar Topographic Mission (SRTM) [14]. The data was then subjected to pixel-based (Random Forest) and object-based (Recursive Hierarchical Segmentation) classifications, yielding results comparable to FAO reports [14].

\subsection{Disaster Management and Earth Sciences}

Earth science related research, as well as studies that directly address disaster extent and response, were done across the globe and reported in this issue. A snowcloud hydro model, applicable to different environments in Chile, Spain, and the USA was developed using MOD10A1 [15]. The cloud-based model forecasts monthly stream flows in snow areas and mapped snow cover areas and is generally applicable. With respect to disasters, [16] developed a flood prevention and response system using the cloud based GEE platform. The system integrates a whole range of datasets from remote sensing and ancillary sources at each stage of flood events (before, during and after) including Formosat-2, Synthetic aperture radar, and GIS topographic data, and was successfully tested to manage the Typhoon Soudelor in August 2015. The GEE platform was also used to assess drought occurrence using soil moisture as an indicator at a global scale [17]. The cloud based engine facilitated an integration of soil moisture global data sets and web-based processing tools to forecast drought duration as well as intensity and the model was successfully tested in Ethiopia and South Africa [17].

Other applications in this issue include cloud masking using multi-temporal approaches [18], surface sediment monitoring [19], and mining area mapping using sentinel data [20].

In summary, this issue has demonstrated the power of GEE platform in handling huge data sets at various scales and building automated programs that can be used at an operational level. This is a great step in solving environmental problems affecting the earth and is critical in achieving the UN millennium development goals. The applications demonstrated are wide ranging, from mining, agriculture, ecosystem services, and drought monitoring, among others. Day to day, monthly, seasonal and long-term monitoring of phenomena at high spatial resolution and covering large extents is now possible with the availability of such platforms that can handle big data.

Acknowledgments: This work was supported by the DST/NRF Chair in Land use planning and management, Grant No. 84157.

Conflicts of Interest: The authors declare no conflict of interest.

\section{References}

1. Kumar, L.; Mutanga, O. Google Earth Engine Applications Since Inception: Usage, Trends, and Potential. Remote Sens. 2018, 10, 1509. [CrossRef]

2. Campos-Taberner, M.; Moreno-Martínez, Á.; García-Haro, F.J.; Camps-Valls, G.; Robinson, N.P.; Kattge, J.; Running, S.W. Global Estimation of Biophysical Variables from Google Earth Engine Platform. Remote Sens. 2018, 10, 1167. [CrossRef]

3. Poortinga, A.; Clinton, N.; Saah, D.; Cutter, P.; Chishtie, F.; Markert, K.N.; Anderson, E.R.; Troy, A.; Fenn, M.; Tran, L.H.; et al. An Operational Before-After-Control-Impact (BACI) Designed Platform for Vegetation Monitoring at Planetary Scale. Remote Sens. 2018, 10, 760. [CrossRef]

4. Tsai, Y.H.; Stow, D.; Chen, H.L.; Lewison, R.; An, L.; Shi, L. Mapping Vegetation and Land Use Types in Fanjingshan National Nature Reserve Using Google Earth Engine. Remote Sens. 2018, 10, 927. [CrossRef] 
5. Robinson, N.P.; Allred, B.W.; Jones, M.O.; Moreno, A.; Kimball, J.S.; Naugle, D.E.; Erickson, T.A.; Richardson, A.D. A Dynamic Landsat Derived Normalized Difference Vegetation Index (NDVI) Product for the Conterminous United States. Remote Sens. 2017, 9, 863. [CrossRef]

6. Goldblatt, R.; Rivera Ballesteros, A.; Burney, J. High Spatial Resolution Visual Band Imagery Outperforms Medium Resolution Spectral Imagery for Ecosystem Assessment in the Semi-Arid Brazilian Sertão. Remote Sens. 2017, 9, 1336. [CrossRef]

7. Parente, L.; Ferreira, L. Assessing the Spatial and Occupation Dynamics of the Brazilian Pasturelands Based on the Automated Classification of MODIS Images from 2000 to 2016. Remote Sens. 2018, 10, 606. [CrossRef]

8. Traganos, D.; Aggarwal, B.; Poursanidis, D.; Topouzelis, K.; Chrysoulakis, N.; Reinartz, P. Towards Global-Scale Seagrass Mapping and Monitoring Using Sentinel-2 on Google Earth Engine: The Case Study of the Aegean and Ionian Seas. Remote Sens. 2018, 10, 1227. [CrossRef]

9. Lee, J.; Cardille, J.A.; Coe, M.T. BULC-U: Sharpening Resolution and Improving Accuracy of Land-Use/Land-Cover Classifications in Google Earth Engine. Remote Sens. 2018, 10, 1455. [CrossRef]

10. Ravanelli, R.; Nascetti, A.; Cirigliano, R.V.; Di Rico, C.; Leuzzi, G.; Monti, P.; Crespi, M. Monitoring the Impact of Land Cover Change on Surface Urban Heat Island through Google Earth Engine: Proposal of a Global Methodology, First Applications and Problems. Remote Sens. 2018, 10, 1488. [CrossRef]

11. He, M.; Kimball, J.S.; Maneta, M.P.; Maxwell, B.D.; Moreno, A.; Beguería, S.; Wu, X. Regional Crop Gross Primary Productivity and Yield Estimation Using Fused Landsat-MODIS Data. Remote Sens. 2018, 10, 372. [CrossRef]

12. Mahdianpari, M.; Salehi, B.; Mohammadimanesh, F.; Homayouni, S.; Gill, E. The First Wetland Inventory Map of Newfoundland at a Spatial Resolution of $10 \mathrm{~m}$ Using Sentinel-1 and Sentinel-2 Data on the Google Earth Engine Cloud Computing Platform. Remote Sens. 2018, 11, 43. [CrossRef]

13. Aguilar, R.; Zurita-Milla, R.; Izquierdo-Verdiguier, E.; de By, R.A. A Cloud-Based Multi-Temporal Ensemble Classifier to Map Smallholder Farming Systems. Remote Sens. 2018, 10, 729. [CrossRef]

14. Xiong, J.; Thenkabail, P.S.; Tilton, J.C.; Gumma, M.K.; Teluguntla, P.; Oliphant, A.; Congalton, R.G.; Yadav, K.; Gorelick, N. Nominal 30-m Cropland Extent Map of Continental Africa by Integrating Pixel-Based and Object-Based Algorithms Using Sentinel-2 and Landsat-8 Data on Google Earth Engine. Remote Sens. 2017, 9 , 1065. [CrossRef]

15. Sproles, E.A.; Crumley, R.L.; Nolin, A.W.; Mar, E.; Lopez Moreno, J.I. SnowCloudHydro-A New Framework for Forecasting Streamflow in Snowy, Data-Scarce Regions. Remote Sens. 2018, 10, 1276. [CrossRef]

16. Liu, C.-C.; Shieh, M.-C.; Ke, M.-S.; Wang, K.-H. Flood Prevention and Emergency Response System Powered by Google Earth Engine. Remote Sens. 2018, 10, 1283. [CrossRef]

17. Sazib, N.; Mladenova, I.; Bolten, J. Leveraging the Google Earth Engine for Drought Assessment Using Global Soil Moisture Data. Remote Sens. 2018, 10, 1265. [CrossRef]

18. Mateo-García, G.; Gómez-Chova, L.; Amorós-López, J.; Muñoz-Marí, J.; Camps-Valls, G. Multitemporal Cloud Masking in the Google Earth Engine. Remote Sens. 2018, 10, 1079. [CrossRef]

19. Markert, K.N.; Schmidt, C.M.; Griffin, R.E.; Flores, A.I.; Poortinga, A.; Saah, D.S.; Muench, R.E.; Clinton, N.E.; Chishtie, F.; Kityuttachai, K.; et al. Historical and Operational Monitoring of Surface Sediments in the Lower Mekong Basin Using Landsat and Google Earth Engine Cloud Computing. Remote Sens. 2018, 10, 909. [CrossRef]

20. Lobo, F.D.L.; Souza-Filho, P.W.M.; Novo, E.M.L.d.M.; Carlos, F.M.; Barbosa, C.C.F. Mapping Mining Areas in the Brazilian Amazon Using MSI/Sentinel-2 Imagery (2017). Remote Sens. 2018, 10, 1178. [CrossRef]

(C) 2019 by the authors. Licensee MDPI, Basel, Switzerland. This article is an open access article distributed under the terms and conditions of the Creative Commons Attribution (CC BY) license (http://creativecommons.org/licenses/by/4.0/). 